\title{
Reemployment of Dislocated Workers in Urban China: The Roles of Information and Incentives"
}

\author{
John Giles \\ Department of Economics \\ Michigan State University \\ (gilesj@msu.edu)
}

\author{
Albert Park \\ Department of Economics \\ University of Michigan \\ (alpark@umich.edu)
}

Fang Cai

Institute for Population and Labor Economics

Chinese Academy of Social Sciences

(caifang@cass.org.cn)

This Version: June 11, 2006

First Version: June 1, 2003

JEL Codes: J20, J22, J60, J64, J65, O10, P20, Z13

Keywords: Social Networks, Unemployment Duration, Dislocated Workers, Unemployment Insurance, Urban China

Corresponding Author: John Giles, Department of Economics, 110 Marshall-Adams Hall, East Lansing, MI 48824 (gilesj@msu.edu).

\footnotetext{
* The authors have benefited from discussions with Dwayne Benjamin, Tito Boeri, Loren Brandt, Simon Commander, Thomas DeLeire, Steven Haider, Benjamin Read, Andrei Shevchenko, Jan Svejnar, and Katherine Terrell. Giles gratefully acknowledges support for research presented in this paper from the European Bank for Reconstruction and Development and the Japan-Europe Cooperation Fund. The authors gratefully acknowledge grants to support field research from Michigan State University (Intramural Research Grants Program), the Chinese Academy of Social Sciences, Ford Foundation (Beijing), the University of Michigan (Rackham Faculty Research Grant), the Australian Research Council, the International Centre for the Study of East Asian Development (ICSEAD), and the World Bank (Beijing), and support for follow-up research from the Weatherhead Center for International Affairs at Harvard University (Academy Scholars Program) and the W.E. Upjohn Institute for Employment Research.
} 


\begin{abstract}
Using original survey data from China, we estimate a discrete duration model to study the reemployment of urban workers who lost jobs involuntarily during the restructuring of China's state sector. Taking the number of relatives living in the same city as an exogenous measure of social networks, we provide empirical evidence of the importance of these networks in job search. In contrast to studies of other transition economies, our results suggest that access to unemployment subsidies reduces the probability of reemployment within a year by 34 percent for men. Unlike men, women's reemployment is not responsive to public subsidies, although it is responsive to family circumstances. Women with children of college age are reemployed faster, especially if the local community provides employment referral services, while women with older adult children are less likely to be reemployed within a year.
\end{abstract}




\section{Introduction}

Because extended periods of unemployment can be very costly to workers and their families and can influence aggregate macroeconomic outcomes, labor economists have had a longstanding interest in understanding the factors that determine whether and how quickly dislocated workers return to work. Most early studies of reemployment rates use micro-data from the U.S. and focus on whether specific features of unemployment insurance programs create disincentives to search for new work. This research confirms significant disincentive effects from increasing both the duration and level of unemployment benefits. ${ }^{1}$ More recently, this question has received renewed attention in transition economies as governments have struggled to balance the political pressure to provide generous safety nets to dislocated state-sector workers with the desire to speed structural adjustment and avoid costly welfare programs. Surprisingly, recent studies of reemployment in Eastern European transition economies have not found strong evidence that unemployment insurance creates a disincentive to return to work. ${ }^{2}$

One explanation for lower reemployment responsiveness to unemployment benefits or to other incentives is that institutional factors impede the process of job search in transition economies. Formal institutions supporting job search, such as public and private employment centers or temporary employment agencies, may be nonexistent. If they do exist, these institutions are frequently new, unfamiliar, inconvenient, or ineffective. Moreover, individuals who previously had one government-assigned lifetime job are unfamiliar with the process of job search and may be isolated from information about job opportunities, creating disorganization

\footnotetext{
${ }^{1}$ Hamermesh (1977) and Devine and Kiefer (1991) review early research documenting the disincentive effects of unemployment insurance. In the U.S., a 10 percent increase in the wage replacement rate is found to increase unemployment duration by a range between 0.3 weeks according to Davidson and Woodbury (1996) and 1.5 weeks according to Katz and Meyer (1990).

${ }^{2}$ Various authors discuss this issue for other countries, e.g., Bellmann et al. (1995) for former East Germany, Ham, Svejnar and Terrell (1998, 1999) for the Czech Republic and Slovakia, Micklewright and Nagy (1994, 1996) for Hungary, and Puhani (2000) for Poland.
} 
that slows adjustment, as suggested by Blanchard and Kremer (1997). In China, laid-off statesector workers often live in housing provided by their former employers so that they are surrounded by other displaced workers and geographically isolated from the employed workforce. In this context, the ability to make use of social networks that extend beyond the neighborhood or the work unit may play a critical role in one’s ability to find a new job.

In this paper, we examine the role of information and incentives on reemployment by taking advantage of data from a survey of urban workers in China that both enumerated work histories and asked detailed questions about non-employment spells, access to public subsidies, resident and non-resident family members, family social networks, and the neighborhood in which the household is located. The empirical analysis focuses on estimating how reemployment hazard rates are affected by public subsidies, private incentives, especially those related to family demographics, and access to social networks and to other information sources. We focus on the number of relatives living in the same city as a preferred exogenous measure of a worker's social network. We also study the impact of neighborhood-based job referral services.

We provide a rigorous analysis of factors affecting reemployment of dislocated workers following the large-scale economic restructuring that took place in China during the late 1990s. Economic restructuring affected tens of millions of workers and continues to have important ramifications for China's labor market and economic reform prospects. The Chinese case is compelling because of the magnitude of the shocks caused by restructuring and because of China's importance as the world's largest transition economy and developing country. Previous studies of the reemployment of urban workers in China use survey data that are unlikely to be representative. ${ }^{3}$ In addition, the Chinese case affords several advantages for identifying the

\footnotetext{
${ }^{3}$ We use a representative sample of all urban workers and unemployed workers in five large cities. Appleton et al. (2002) over-sample retrenched workers. If this over-sampling involved sampling workers from administrative
} 
effects of information and incentives on the probability of workers' reemployment. Benefit coverage for unemployed urban workers was highly uneven due to failures in the public financing of benefits; hence, we have plausibly exogenous variation in access to benefit coverage. At this time, most urban Chinese people still lived in housing units originally provided by their employers so that the mobility of urban residents in China remains limited; this effect reduces the self-selection of individuals into specific neighborhoods.

Dislocated workers in China consider a number of factors when deciding whether and how to search for a new job. New public programs provide subsidies to the unemployed but coverage is incomplete and benefits have been subject to frequent revision. Vulnerable groups, such as women, less-educated people, and older workers, have had great difficulty finding jobs. For workers leaving the state sector, available new jobs may be much more demanding for similar or lower pay than their previous jobs and may lack comparable social status. Before reforms, China had one of the highest female labor force participation rates in the world. Similar to many other transition economies studied by Svejnar (1999) and Ham et al. (1999), China has witnessed a marked reduction in labor force participation, particularly for women, during the restructuring period. For some women, the returns to home production, such as caring for children or the elderly, may have become more attractive than any realistic employment opportunities. On the other hand, the combination of credit constraints and the rapidly increasing costs of educating children and purchasing homes during the period under study could have led to increased labor supply.

The paper is organized as follows. In Section 2, we summarize briefly the research on the importance of social networks in job search and present a simple theoretical model to motivate

records of xiagang workers, the sample over-represents workers who have a potential claim to formal support even if former work-units or city governments have not yet provided it. 
the empirical work. In addition, we describe the China Urban Labor Survey (CULS) data. In section 3, we discuss the process of economic restructuring in urban China, the government's subsidy programs for dislocated workers, and the job search process in China. In section 4, we introduce the empirical hazard model and identify specific variables and important identification assumptions used in the empirical analysis. In section 5, we present the estimation results. A final section discusses the implications of our findings.

\section{The Model and the Data}

The important role of social networks in the process of job search is now wellrecognized. Using survey-based evidence, Montgomery (1991) concludes that approximately 50 percent of all new jobs in the U.S. are found through referrals facilitated by social networks. Previous research finds that the importance of social networks for finding jobs has increased over time in the U.S. and that men, less-educated people, and those living in poorer neighborhoods are more likely to rely upon social networks in job search (Ionnides and Datcher-Loury, 2004) discuss. Pellizzari (2004) finds that the importance of social networks in job search varies substantially across countries but little research on this topic includes developing and transition economies. Recently, Calvo-Armengol and Jackson (2004) have shown theoretically that social networks can explain positive correlations between the employment outcomes of network members both within and between periods.

To motivate our empirical work, we extend a standard model of job search to incorporate the role of access to information. A worker who has lost his job maximizes the expected discounted value of future income given by:

$$
\operatorname{Max} \sum_{t=0}^{\infty} \beta^{t} y_{t}
$$


where $y_{t}=w$ if employed, $y_{t}=b$ if not employed, and $\beta$ is the one-period discount rate. ${ }^{4}$ In this specification, $w$ includes wages and other benefits associated with employment and $b$ represents the benefits received when not employed, which consist of government subsidies, returns from home production, and the value of leisure. The worker receives wage offers in each period that are individually and identically distributed and drawn from an exogenously given wage distribution, denoted $f(w)$. If the worker accepts a job, he earns $w$ forever. The worker's optimal strategy is to accept all wage offers that are greater than an endogenously determined optimal reservation wage, denoted $w_{R}$.

The optimal reservation wage is defined implicitly as follows: ${ }^{5}$

$$
w_{R}=b+\frac{\alpha(s)}{r} \int_{w_{R}}^{\infty}\left(w-w_{R}\right) d F(w)
$$

In this case, the worker is indifferent between accepting a permanent wage offer of $w_{R}$ and rejecting this offer to earn $b$ in the current period and a positive probability of earning more than $w_{R}$ in the future. In this specification, $\alpha(s)$ is a parameter that determines the arrival rate of job offers, which follows a Poisson process. We assume that this rate is an increasing function of $s$, which denotes the sources of information available to the worker. ${ }^{6}$

The hazard rate for accepting a new job in this framework is $\lambda=\alpha\left[1-F\left(w_{R}\right)\right]$, which is the arrival rate of offers multiplied by the probability that the offer is above the reservation wage. To investigate the impact on the hazard rate for job acceptance of changes in $b$ and $s$, we examine the first-order conditions:

\footnotetext{
${ }^{4}$ For tractability, we make the common assumption in all periods that $\beta=\frac{1}{1+r}$, where $r$ is the interest rate.

${ }^{5}$ Rogerson and Wright (2003) and Neumann (1997) provide more detailed derivations.

${ }^{6}$ Based on our identification strategy, we do not allow endogenous search intensity. Rather, we assume that the arrival rate of offers depends on exogenous access to information sources.
} 


$$
\begin{aligned}
& \frac{\partial \lambda}{\partial b}=-\alpha\left[1-F\left(w_{R}\right)\right] \frac{\partial F}{\partial w_{R}} \frac{\partial w_{R}}{\partial b}<0, \text { and } \\
& \frac{\partial \lambda}{\partial s}=\left[1-F\left(w_{R}\right)\right]\left(\frac{\partial \alpha}{\partial s}-\alpha \frac{\partial F}{\partial w_{R}} \frac{\partial w_{R}}{\partial s}\right) .
\end{aligned}
$$

From (2), the reservation wage is increasing in both $b$ and $s$ so that $\frac{\partial w_{R}}{\partial b}>0$ and $\frac{\partial w_{R}}{\partial s}>0$. Hence, a higher value of $b$ raises the reservation wage and reduces the hazard rate for reemployment. The effect of a larger $s$ on the hazard rate cannot be signed unambiguously. On one hand, a faster arrival rate due to a higher value for s means that the individual is getting more offers per period, which increases the hazard rate. On the other hand, the individual's anticipation of faster-arriving offers raises the reservation wage and reduces the hazard rate. Most empirical work hypothesizes that the former effect outweighs the latter one; based on this assumption, better information increases the likelihood of reemployment. $^{7}$

We also are interested in the interaction between information sources and benefits. To understand the nature of the interaction effects, we examine the following cross-partial derivative: ${ }^{8}$

$$
\frac{\partial \lambda^{2}}{\partial b \partial s}=\frac{\partial \lambda^{2}}{\partial s \partial b}=-\frac{\partial F}{\partial w_{R}} \frac{\partial w_{R}}{\partial b} \frac{\partial \lambda}{\partial s}-\alpha\left[1-F\left(w_{R}\right)\right] \frac{\partial F}{\partial w_{R}} \frac{\partial w_{R}}{\partial b \partial s}
$$

\footnotetext{
${ }^{7}$ In practice, a larger social network may be an exhaustible source of faster job offers. If workers recognize this, they will not consider a higher rate of job offers to be permanent. Hence, the likelihood that greater s will affect reemployment probabilities positively increases.

${ }^{8}$ For this derivation, we have treated $\frac{\partial F}{\partial w_{R}}$ as constant, as in a uniform distribution. Without making assumptions about the distribution of $w_{R}$, no clear predictions can be made.
} 
The sign of the first term in (5) depends on the impact that more information has on the job acceptance rate; it will be negative if $\frac{\partial \lambda}{\partial s}>0$, suggesting that better information makes reemployment more sensitive to incentives. However, the sign of the second term is positive because $\frac{\partial w_{R}}{\partial b \partial s}<0$. With better search ability due to more information about prospective employment, the impact of benefits on the reservation wage is reduced. With better search, the effect of increasing the reservation wage on the expected future wage is magnified due to the expectation of more offers, so that an increase in benefits during non-employment requires a smaller adjustment in the reservation wage to satisfy the equilibrium condition given in (2). Hence, the sign of expression (5) is ambiguous. In our empirical specification, the benefits variable, $b$, includes explicit sources of government support, e.g., pensions and unemployment insurance, along with family demographic features that may have a positive or negative effect on the benefits of non-employment. Measures of access to information, $s$, include characteristics of the local extended family network and an indicator for the presence of neighborhood employment referral.

Overall, the model predicts that increases in $b$ will lead to longer periods out of the workforce but it provides less guidance on the effect of changes in information access and the interaction of access to information and benefits on non-employment. This model of individual job search illuminates the ways in which information and incentives affect individual reemployment probabilities. Although useful for microeconomic applications, the model fails to account for general equilibrium effects that may be important for making policy assessments as Mortenson and Pissarides (1999) and Rogerson and Wright (2002) discuss. For example, 
employers might respond to the unemployment rate and policy changes by altering the rate at which they make offers, the amount of the offers, and the rate at which current workers are dismissed. All of these reactions influence equilibrium employment outcomes but consideration of them is beyond the scope of this paper.

The China Urban Labor Survey (CULS) was conducted in November 2001 by the Institute for Population and Labor Economics at the Chinese Academy of Social Sciences (CASS-IPS), working with provincial and municipal offices of the National Bureau of Statistics. All three authors collaborated in the design and execution of the survey. The CULS was conducted in five cities, namely, Fuzhou, Shanghai, Shenyang, Wuhan, and Xian. ${ }^{9}$ In this paper, we study only individuals living in households having local urban permanent residence permits. We do not consider people with temporary residence permits or with no registration status; this group consists primarily of rural migrants. China maintains a household registration (hukou) system that determines access to employment and to many social services and benefits. Our objective is to study the impact of recent changes on urban workers who were previously protected under the socialist system. Hence, we focus on urban-registered households. ${ }^{10}$ Changing registration status is not easy and permanent-registered urban residents of cities are long-term residents. In the 2000 Population Census, individuals with registered local urban residence comprise 76 percent of those living in the five sample cities. In the CULS, 78 percent of the urban registered residents were born in the city. Among working-age residents in the CULS, only 12.9 and 5.2 percent have lived in the city for fewer than 20 and 10 years, respectively.

\footnotetext{
${ }^{9}$ Extensive discussion of the sampling and survey design can be found in Giles et al. (2006) and from the discussion of survey protocol available on-line at http://www.msu.edu/ gilesj.

${ }^{10}$ The CULS includes a separate survey of migrants but the data from that part of the survey are not used in this study.
} 
The CULS includes individual calendar-based work histories with detailed questions about job changes and transitions to unemployment or retirement in addition to questions on changes in pension, health care, and housing benefits and on access to government social insurance programs from January 1996 to November $2001 .{ }^{11}$ Since we also know the start date of non-working spells, we avoid a common problem of left-censoring by using non-working periods that began before 1996 and were continuing at the start of our reference period. Workers also provided information on their close relatives and social contacts. Separate household and neighborhood questionnaires were administered; these provide basic information on all household members and neighborhood characteristics, including services provided by community organizations.

\section{Institutions, Economic Restructuring and Job Search in Urban China}

During the late 1990s, widespread financial insolvency of China's state-owned urban enterprises forced the central government to end a long-standing commitment to lifetime statesector employment for the vast majority of urban residents. For the first time since the Peoples Republic of China was established in 1949, urban unemployment became a serious problem, reaching double digits by the turn of the century in large Chinese cities, as reported by Giles, Park, and Zhang (2005). According to official statistics, over 25 million workers were officially laid off from 1998 to 2002. ${ }^{12}$ From 1996 to 2002, the total number of state-sector workers declined from 112.6 million to 71.6 million, which is a decrease of 36.4 percent. The decline in collective-sector employment was even more dramatic. According to the CULS data, the percentage of working-age adults, i.e., people aged 17 to 60, who were employed fell from 77.4 percent in January 1996 to 65.1 percent in November 2001.

\footnotetext{
${ }^{11}$ English language translations of the CULS instruments can be found at: http://www.msu.edu/ gilesj/

${ }^{12}$ In China, xiagang or being laid off is an official registered status entitling individuals to special subsidies.
} 
We focus on dislocated workers, whom we define to be those who were involuntarily out of work from January 1996 to October 2001. To distinguish involuntary from voluntary job separations, we examine self-reported explanations for the end of employment for all prior job spells. ${ }^{13}$ Enterprise restructuring is considered to be the reason for job loss if the respondent chooses one of the following responses: work unit closed, went bankrupt, or was merged or reorganized. Other involuntary reasons for job separations include forced early retirement and other involuntary dismissals. The remaining reasons for job separations are voluntary departures, mandatory retirement, and other. Overall, 60.3 and 64.4 percent of job separations of men and women, respectively, were involuntary. Of these 29.0 and 21.8 percent related directly to restructuring, 15.6 and 31.1 percent were due to forced early retirement, and 15.8 and 11.4 percent were classified as other involuntary dismissals. Only 25.9 and 19.0 percent of job separations, respectively, were voluntary. Even if we allow for reporting bias by disgruntled workers, China stands in stark contrast to other transition economies in the predominantly involuntary nature of job separations.

The non-employment benefits most relevant for policy are public subsidies provided to job-losers. To ease the pain of labor-force adjustment, the Chinese government established new social welfare programs. A special policy to support officially laid off, or xiagang, workers was implemented nationwide in 1998. Intended for permanent workers employed before labor contracting began in 1986 or for contract workers whose jobs ended before their contracts expired, this policy provides three years of basic living subsidies at 60 percent of the worker's final wage in addition to health insurance and pension contributions. ${ }^{14}$ Laid off workers retain formal ties to their former work units until they find a new job but they are expected to register

\footnotetext{
${ }^{13} \mathrm{~A}$ breakdown of job separations by demographic category can be found in Table $\underline{4}$ of Giles, Park, and Cai (2006).

${ }^{14}$ Benefits often declined over time and subsidies were intended to be greater than unemployment insurance subsidies. However, actual benefit amounts depended greatly on the financial resources of the municipality.
} 
with newly established reemployment centers designed to provide skill training and assistance in finding new jobs. ${ }^{15}$ The xiagang subsidies drew upon unemployment insurance funds in addition to central and local budgetary expenditures and enterprise contributions. They were intended to be temporary policy and end on January $1,2001 .{ }^{16}$ However, in many cities, benefits were maintained beyond 2001. As Giles, Park and Cai (2006) report, many cities and enterprises lacked sufficient funds so that the program failed to reach a large share of dislocated workers who in principle should have qualified for benefits.

In 1999, the government standardized its unemployment insurance program, which is designed to provide coverage to all workers regardless of whether they are employed in the state, collective, or private sectors. The program is financed by payroll charges and provides subsidies for up to two years depending on how long the worker and the employer participated in the unemployment insurance program. Workers whose three years of xiagang subsidies expire became eligible immediately for unemployment benefits. Hence, some workers who were laid off from the state sector could have had access to five years of public subsidies while unemployed. ${ }^{17} \mathrm{~A}$ final source of public subsidies for unemployed workers is early pension payments provided to individuals who are pressured to retire before reaching official retirement age. The amounts of such payments are negotiated between workers and their employers; these are typically less than regular pension payments. In principle, nothing prohibits such workers from reentering the workforce.

\footnotetext{
${ }^{15}$ Once workers find new employment, they are no longer legally eligible for unemployment subsidy payments, either xiagang or registered unemployment. However, information from the CULS suggests that some workers were able to continue collecting benefits. In November 2001, 39.9 percent of dislocated workers who received subsidies continued to collect unemployment subsidies after finding new employment.

${ }^{16}$ In practice, many local governments extended benefits to 2003 and beyond, as Zhang (2003) documents.

${ }^{17}$ By 1998, many cities also began providing relief through a minimum living standard program (MLSP) that targeted households whose income per capita fell below designated urban poverty lines set by each city. Because these funds reached very few households during the period under study and were not targeted at individuals, we do not consider them in the empirical analysis.
} 
Figure 1 depicts the share of working age adults in different demographic groups who were dislocated and out of work and divides these individuals into three categories, namely the share with access to xiagang subsidies or unemployment insurance indicated by gray dots, the share receiving pension payments indicated in white, and the share lacking access to public support indicated in black. The figure reveals that large fractions of younger and middle-aged workers lack access to public benefits, that younger workers are much less likely to have access to public benefits than are older workers, and that, among middle-aged workers, women are much less likely than men to receive unemployment benefits. ${ }^{18}$

When we compare access to benefits across firms of different ownership structures, we observe significant differences in average benefit coverage rates. Workers previously employed in state-sector firms, which include majority state-owned firms, and in collective-sector firms are much more likely to have some source of support, although coverage rates are not complete. Among involuntarily out-of-work adults, 76.2 and 70.2 percent of those formerly employed in the state and collective sectors, respectively, receive some subsidy compared to only 48.5 percent overall.

Apart from the availability of formal support, household and family characteristics may affect individual labor-supply decisions. However, these are generally unobservable to employers so that they should not influence the demand for labor. For example, living with children below college age could increase demands on parental time, especially for women, and raise the value of not working. With imperfect credit markets, a household with a child in college may increase

\footnotetext{
${ }^{18}$ Women are less likely to receive unemployment benefits because they are eligible for early retirement with a pension at a much younger age than men. Because pension receipt is a permanent benefit with a higher replacement rate, it is more attractive way for women who can make a choice between layoff or early-retirement.
} 
labor supply to pay for rising tuition costs. ${ }^{19}$ Table 1 reports that 26 percent of men and 28 percent of women had an adult child of college age at the time of dislocation. In addition, twenty-one percent of both men and women had children aged 23 to 28 living in the same city while 38 percent of men and 31 percent of women had children aged 28 and older living in the same city. Cai et al. (2006) argue that older adult children could have a positive or negative effect on their parents' labor supply depending on whether these children are net providers or net recipients of intergenerational transfers or care-giving.

As in many other countries, job search in China is dominated by the use of social networks and the extended family is likely to figure prominently in such networks. Among dislocated workers who were reemployed, 42 percent of men and 40 percent of women were referred to their new employers by relatives and friends. By comparison, 24 percent of men and 32 percent of women learned of their new job through radio broadcasts or newspaper ads and 21 percent of both men and women were referred through a reemployment center or other government agency. The Chinese government has been very concerned about the reemployment of dislocated state-sector workers. The government passed regulations mandating that employers who laid off large numbers of employees establish reemployment centers to provide skill training and job referral services for workers, and Zhang (2003) reports that these regulations required that workers receiving xiagang subsidies avail themselves of these services. However, in reality, only 12 percent of the xiagang workers in our sample report that they were requested to participate in any training activities and many of these did not even bother to attend the sessions.

One Chinese institution that has received relatively little attention is the local residents' committee (RCs), which are neighborhood organizations established and governed by municipal

\footnotetext{
${ }^{19}$ Even with expanding university capacity and enrollments after 1995, the burden of covering the cost of university education was shifted onto students and their families. Existing student loan programs do not provide sufficient funds to cover more than a fraction of tuition costs for a small share of university students (Du and Giles, 2006).
} 
governments. ${ }^{20}$ At the time of our survey, the Ministry of Civil Affairs was in the process of strengthening and professionalizing RCs by mandating higher fixed salaries for RC members, raising minimum education requirements, and expanding the services that RCs provide to local communities. ${ }^{21}$ Employment referral was provided by the RC in 226 of 356 communities surveyed in 2001 and it has a long history in some RCs. In most cases, the referral service consists of a list of local employers, e.g., restaurants, shops, enterprises, private housing developments, and households, that have contacted the RC and expressed interest in hiring workers. Lack of information about the timing of introduction of employment referral services makes it difficult for us to analyze their impact in a treatment-control framework. To assess the contribution of this service, we take a reduced-form approach: we include a dummy for presence of employment referral and then control for neighborhood characteristics that are likely to affect the supply of and demand for referral services. Other formal institutions that could play a role in job search include employment agencies, organized labor markets, and training programs provided by government or social organizations. However, data limitations prevent us from examining their role in job search.

\section{The Empirical Model: Identifying the Roles of Incentives and Information}

In this section, we present Kaplan-Meier non-parametric estimates of non-employment survival functions for dislocated male and female workers, disaggregated by educational attainment, age category, access to unemployment insurance, and the size of social networks.

\footnotetext{
${ }^{20}$ The residents' committee is sometimes referred to as the neighborhood committee in English and it is known as the jumin weiyuanhui or the shequ in Chinese. Residents' committee is the term adopted and favored by Choate (2000) and Read (2003); we follow their terminology.

${ }^{21}$ Professionalizing the RCs has been a long-term process the beginning of which many observers date to 1989 , when new laws were adopted to strengthen RCs after they had languished throughout the 1980s. Read $(2000,2003)$ provides detailed discussions of the history of RCs and the services that they have provided. Read's observations suggest that employment referral is not entirely new but that it evolved from an earlier practice of RCs setting up small enterprises to employ and train young adults who were waiting for work and not yet assigned to work units under the socialist system.
} 
Although these estimates are descriptive, they motivate the subsequent multivariate analysis of reemployment rates. Our primary tool for analyzing reemployment rates is the discrete time hazard model used by Kalbfleisch and Prentice (1980) and Lancaster (1990). The transition probability or hazard rate, denoted $\lambda(\mathbf{t}, \mathbf{Z})$, is the probability of leaving a state in period $t$ conditional on both a continuous presence in this state for the previous $t-1$ periods and a set of covariates, denoted $\mathbf{Z}$. In the most general form, the covariate vector varies by individual $i$, in neighborhood $j$, in city $k$, and at time $t$. The hazard rate, $\lambda\left(\mathbf{t}, \mathbf{Z}_{i j k t}\right)$ is modeled as a logit function so that we have:

$$
\lambda\left(\mathbf{t}, \mathbf{Z}_{i j k t}\right)=\frac{\exp \left(\boldsymbol{\alpha}_{t}+\mathbf{Z}_{i j k t} \Pi\right)}{1+\exp \left(\boldsymbol{\alpha}_{t}+\mathbf{Z}_{i j k t} \Pi\right)}
$$

The logit specification allows for time-varying covariates and a flexible form for the effect of time on the likelihood of reemployment in the next period. ${ }^{22}$ The vector $\boldsymbol{\alpha}_{t}$ consists of indicator variables for the length of non-working spells for each of the first six months after separation and a quartic term for each month from 7 to 96 after separation. ${ }^{23}$ The combined time dummies and quartic terms provide a non-parametric control for the duration properties of the model. Exit probabilities are scaled up or down by time-varying covariates, $\mathbf{Z}_{i j k t}$.

The general and most inclusive specification for $\mathbf{Z}_{i j k t}$ is:

$$
\mathbf{Z}_{i j k t} \Pi=\mathbf{X}_{i j k t} \gamma_{1}+\mathbf{B}_{i j k t}^{\prime} \gamma_{2}+\mathbf{S}_{i j k t}^{\prime} \gamma_{3}+\left(\mathbf{B}_{i j k t} \otimes \mathbf{S}_{i j k t}\right)^{\prime} \gamma_{4}+\text { city }_{k}+\text { year }_{t}
$$

\footnotetext{
${ }^{22}$ The logit specification of the discrete hazard model does not place any parametric assumptions on the functional form of the hazard; it has additional appeal because the data are recorded in discrete one-month intervals. The Cox proportional hazard and other hazards models are popular because imposing structural assumptions on the hazard can produce more efficient estimates. However, greater efficiency is accompanied with the risk that coefficient estimates may be biased due to inappropriate functional form assumptions. Meyer (1995) provides a detailed comparison of the properties of the discrete duration model and other more parametric approaches. Researchers working in the literature on welfare duration, e.g., Bane and Ellwood (1983), Blank and Ruggles (1996), Ellwood (1986), Hoynes (2000), and Hoynes and McCurdy (1994), and Klerman and Haider (2004) find this property of the discrete time hazard model to be particularly appealing.

${ }^{23}$ The quartic term is $\left(t+t^{2}+t^{3}+t^{4}\right)(6<t<97)$. We include all non-working spells that began after January 1993.
} 
where $\mathbf{X}_{i j k t}$ is a vector of individual worker characteristics and other controls for factors affecting the demand for and supply of labor, the vector $\mathbf{B}_{i j k t}$ contains variables capturing the benefits of non-employment that correspond to the parameter $b$ in the model, $\mathbf{S}_{i j k t}$ contains variables measuring access to information that correspond to the parameter $s$ in the model, and $\mathbf{B}_{i j k t} \otimes \mathbf{S}_{i j k t}$ denotes the interactions of the variables in $\mathbf{B}_{i j k t}$ and $\mathbf{S}_{i j k t}$. In our estimation, we include a set of variables, denoted $\mathbf{X}_{i j k t}$, to control for the effect of individual characteristics and for other key factors affecting the demand for and supply of labor. Even though labor-supply factors determine the benefits of non-employment, many individual characteristics, e.g., human capital, affect both the supply of and the demand for labor contemporaneously. Therefore, such variables are excluded from $\mathbf{B}_{i j k t}$ and given a reduced-form interpretation as variables included in $\mathbf{X}_{i j k t}$. The independent impact of these variables on reemployment rates is of interest in determining which types of individuals are able to find new jobs. These characteristics include years of schooling, prior work experience, and dummy variables for prior ownership sector of employment to proxy for unobserved characteristics of workers that influence their selection into different ownership sectors. ${ }^{24}$

In specification (7), the vector $\mathbf{X}_{i j k t}$ includes controls for demand shocks. Two timevarying components control for city and industrial-sector characteristics of labor demand that may affect reemployment probabilities. We use annual information from 1995 to 2001 from the China Labor Statistical Yearbook on employment by industry sector in the five provinces in which our cities are located to control for local labor demand conditions. Annual changes in the log of the provincial state-owned enterprise employment in the industrial sector of a worker's

\footnotetext{
${ }^{24}$ Unobserved characteristics in workers across sectors related to the ownership sector of prior employment, e.g., differences in work habits, experience, motivation, or access to information about employment in other ownership sectors, may also affect reemployment rates.
} 
prior employment control for shocks to annual labor demand driven by state-sector restructuring. Annual changes in the log of the same type of employment in all other ownership categories capture the effect of changing labor demand conditions in the non-state sector. Workers are classified into 17 broad industrial-sector categories based on their prior sector of employment. Finally, we include two sets of neighborhood variables to control for neighborhood-specific demand and supply conditions in local labor markets. The first group are measures averaged over all other households surveyed in larger neighborhood clusters (jiedao) and include the log of average per capita non-durable neighborhood consumption and time-varying measures of the non-working share of working-age adults. ${ }^{25}$ The second group are variables from the surveys of the RCs (shequ) and include average distance to services, e.g., hospitals, police stations, pharmacies, and the train station, measures of neighborhood size, and housing characteristics.

In specification (7), the vector $\mathbf{B}_{i j k t}$ includes variables that indicate whether or not the dislocated worker has access to publicly provided benefits during the period in addition to a set of variables describing household and family demographics. The main public benefit variable for examining the incentive effects of public subsidy payments is a time-varying dummy variable indicating whether the individual has potential access to xiagang subsidies or registered unemployment benefits. We also include an indicator variable to specify whether the individual receives a pension from early retirement. Since receipt of a pension is not contingent on employment status, this variable can be interpreted as having a wealth or income effect. Although the public-benefit variables indicate whether a person receives benefits, they do not reflect the level of such benefits. One advantage of using a representative sample of all displaced workers is that we are able to exploit plausibly exogenous access to benefits to identify the impact of different support mechanisms on reemployment. Studies on reemployment rates that

\footnotetext{
${ }^{25}$ In each street office (jiedao) administrative area, we surveyed an average of three RCs and ten households per RC.
} 
uses administrative data on participants in a particular benefit program take only a selected sample of displaced workers. Hence, they rely on specific features of the program or on exogenous changes in the program for identification. ${ }^{26}$

The decision not to include the level of benefits in our analysis is an intentional choice to avoid bias due to systematic measurement error and endogeneity. Whether or not benefits are received is salient in the minds of respondents. However, the exact value of benefits is likely to be recalled only with error, particularly if benefit payments vary over a long non-working spell. More importantly, the level of benefits is likely to be highly correlated with unobserved ability. In China, the level of registered unemployment subsidies, early retirement pensions, and xiagang subsidies are dependent upon prior income levels, years of employment, and unobserved dimensions of status in the firm. Thus, all things equal, a worker with a higher subsidy is likely to be of higher ability. This effect creates an upward bias in the measured effect of subsidies on reemployment, which would offset actual negative disincentive effect of benefits on reemployment. Such a bias provides one explanation for the failure by Appleton et al. (2002) to find an effect of the level of benefits on reemployment probabilities in China.

In contrast, access to benefits is likely to be relatively exogenous after conditioning for age, education, and prior ownership sector. Nonetheless, access to benefits may be related to tenure, in which case it will be correlated systematically with ability and impart a positive bias on the coefficient. In urban China, however, job turnover was low prior to reform so that age and education together provide a good proxy for potential tenure as well as experience. When

\footnotetext{
${ }^{26}$ Both Katz and Meyer (1990), which was one of the most influential papers in the general literature, and Ham, Svejnar and Terrell (1998), one of the earliest and most influential of the papers studying reemployment in transition economies, take this approach. In these papers, no standard definition of unemployment is used to define the sample. Rather, the unemployed group consists of those who are eligible for and enroll in particular programs. These authors define their studies as appropriate to the selected sample. We do not exclude dislocated workers who fail to search for new jobs because doing so would introduce selection biases. Search activity itself responds to subsidies and other incentives, as Card and Riddell (1997) discuss, so that distinguishing between unemployed and discouraged workers is often difficult.
} 
required to provide benefits, employers are obligated to provide them to all eligible dislocated workers not only to those with high ability. Moreover, local governments are unlikely to exclude low-ability workers who have bleaker reemployment prospects.

To examine the impact of household and family demographics on labor supply, we include two types of demographic variables. The first group consists of variables describing the composition of the household and the second group comprises characteristics of the number of adult children regardless of whether they are household members. The former include household size, marital status, the number of resident children under 6 , the number of resident children between 6 and 12 years of age, the number of resident children between 12 and 18 years of age, the number of resident retirees over mandatory retirement age but under 65, and the number of resident elderly over age 65 with all age ranges including their lower bounds. The latter include dummy variables to indicate whether the respondent has children aged 18 to 23, children aged 23 to 28 , and children aged 28 and over. The vector $\mathbf{S}_{i j k t}$ includes variables that measure access to job information and social network effects. Under the assumption that the number of relatives is not affected by job search strategies, these data can be used to construct a variety of plausibly exogenous social network variables based on kin relationships. In our analyses, we use the number of own-generation relatives, i.e., siblings and cousins, and the number of a spouse's own-generation relatives living in the city as preferred measures of social networks.

Correlations between the size of social networks and reemployment probabilities could occur through channels other than job search. First, suppose that prosperous families are larger and high-ability individuals tend to come from or marry into prosperous families. Then, the size of the social network could be correlated with unobserved ability. Second, individuals in developing countries have many relatives so that they may forget relatives with whom they have 
had little contact. Moreover, the ability to recall all of one's relatives may be correlated with one's unobserved ability. The survey design used for the CULS reduces this possibility. Initially, the survey asks about the number of siblings and cousins with whom the respondent had contact in the previous year. Then, a more inclusive question about all siblings and cousins within the city is included for which the enumerators prodded respondents to recall potentially forgotten family members. Although it is not possible to test directly whether unobserved ability is confounded with extended family size, we find no statistically significant relationship between family size and years of schooling. Third, in addition to providing information about job opportunities, the social network could act as an insurance mechanism in which resources are transferred to members suffering from negative shocks, e.g., unemployment spells. However, descriptive information from the CULS provided in Giles et al. (2006) suggests that very few households relied significantly on extended family support to cover living expenses after losing a job. $^{27}$

Some papers suggest that neighborhood characteristics, e.g., population, mean education, and income levels, could also be interpreted as social network variables. However, we are concerned that such variables also reflect local labor supply and demand conditions, so we treat them as controls in the vector $\mathbf{X}_{i j k t}$ rather than as information variables. The only exception, and our only variable indicating formal institutions that may facilitate job search, is an indicator variable to capture whether the local RC provides employment referral services. We also control for city and year effects in specification (7) as city $\mathbf{~}_{\mathbf{k}}$ denotes a set of dummy variables to control for city-wide effects and year $_{t}$ denotes dummies that control for annual macroeconomic shocks.

The main remaining identification concern is potential bias from unobserved

\footnotetext{
${ }^{27}$ Only two percent of laid-off respondents in the CULS report that assistance from non-resident family members was their most important source of support while out of work, as reported in Table 9 of Giles, Park and Cai (2006).
} 
heterogeneity. The welfare duration literature, e.g., Hoynes (2000), pays considerable attention to the problem of endogenous migration. In our study, workers more eager to work might move within the city into neighborhoods with employment referral centers. However, in the Chinese case, moves to a new neighborhood are extremely costly for families facing lost income from a lay-off. Indeed, only 3.7 percent of dislocated workers report moving to a new neighborhood after suffering involuntary job loss. ${ }^{28}$ To change locations, unemployed workers would be required to abandon housing that is either still subsidized or was acquired at a bargain price as part of a housing privatization scheme that prevented immediate resale. Then, they would have to move into apartments that are rented or sold at much higher market prices. The prospect that laid off workers are migrating into cities in which they have better social networks is even less likely. Although rural-urban migration has been extensive in China economy over the last 15 years, registered urban residents are not very mobile. Among urban residents in the CULS, only 5.2 percent had moved into the city during the previous 10 years and only 4.4 percent of dislocated urban residents had migrated into the city in the previous ten years. Moreover, exactly seven workers, or only 0.24 percent of the sample, moved into the city after experiencing dislocation. Therefore, we do not believe that laid-off urban workers are moving in large numbers to cities in which they have stronger networks in order to find employment.

Despite our attempt to identify plausibly exogenous regressors, we cannot rule out the possibility that some independent variables may be correlated with unobservable individual characteristics that influence reemployment prospects. For example, high-ability individuals may have larger actual or reported kin networks. In addition, employee referral centers may respond to local labor demand as is typical of the unemployment duration literature. However, we cannot avoid these possibilities altogether because much of the variation of interest, i.e., in benefit

\footnotetext{
${ }^{28}$ Only ten of these workers, or 0.33 percent, moved before finding new employment
} 
access, in social networks, and in family demographics, is inherently cross-sectional. To address these concerns, we exploit the rich detail of the CULS by including a large set of control variables that address the most plausible sources of omitted variable bias. We control for past ownership sector of employment to deal with selection effects, for region-specific demandshocks, and for many neighborhood characteristics. In addition, we regress potentially endogenous regressors on the set of independent variables used in the regressions to check the extent to which they are correlated with observable measures of ability, especially years of schooling, and features of the local labor market.

\section{The Empirical Results}

In Figures 2, 3, 4 and 5, we present non-parametric survivor functions, as developed by Kaplan-Meier (1958), for different subcategories of workers experiencing involuntary job loss. In Figure 2, we observe that younger cohorts of dislocated workers tend to find employment faster than do older cohorts. Figure 3 suggests that the better-educated dislocated workers find new employment more quickly. In addition, men and women with some post-secondary education do not appear to differ as much in the rate of reemployment as men and women with lower levels of education. Figure 4 presents the survivor functions for men and women divided into three categories of access to formal support. First, we find that displaced workers who have secure access to pensions, which are usually more generous than unemployment subsidies, are the least likely to be reemployed. Second, xiagang and registered unemployed workers who have access to less generous temporary benefits exit the non-working state more quickly than do early-retired workers. Third, workers without access to formal support find employment faster than early-retired or registered unemployed workers. As is evident from Figure 1, age and access to formal support appear to be highly correlated; thus, identifying any disincentive effect 
suggested in Figure 4 requires multivariate analyses. Finally, Figure 5 depicts survivor functions by number of own-generation relatives residing in the city. Workers with larger numbers of owngeneration family members living in the same city are reemployed faster than workers having smaller family networks.

To estimate the logit hazard models in specifications (6) and (7), we regress a dummy variable indicating whether a worker is reemployed in the next period on time dummy variables, time quartic terms, and different sets of variables that might shift the reemployment hazard rate. For all models, we show robust standard errors that are cluster corrected at the large neighborhood (jiedao) level. We begin with a basic model in which $\mathbf{Z}_{i j k t} \Pi$ is given by:

$$
\mathbf{Z}_{i j k t} \Pi=\mathbf{X}_{i j k t} \gamma_{4}+\text { city }_{k}+\text { year }_{t} .
$$

In this base specification, we look first at factors influencing reemployment rates before considering the impact of benefits and of the access to information.

Interpreting logit coefficients, or even the economic significance of marginal effects, is often difficult. To grasp both the economic and statistical significance of our results, we calculate the effects of changes in variables on one year reemployment rates, ceteris paribus. For each model, we calculate a baseline monthly hazard rate using an assumed base set of values for all variables and then convert it to an annual hazard rate. We next calculate the twelve-month marginal effect of specific changes in the variables and divide the twelve-month marginal effect by the baseline reemployment rate to measure the economic significance of marginal changes in the important variables.

Results for our simplest specification are presented in columns 1 and 3 of Table 2 confirm that reemployment probabilities are significantly higher for better-educated dislocated workers. An increase in years of education from 12 to 13 years leads to a 5.6 or 12.5 percent increase in 
the probability that men and women, respectively, will be reemployed within a year. Age is negatively related to the probability of reemployment. Increasing age from 40 to 41 leads to a 4.9 percent reduction in the reemployment rate for men and a 7.0 percent fall in the reemployment rate for women. Hence, our results indicate that the reemployment prospects of women are more sensitive to both education and age than are those for men.

Columns (2) and (4) of Table 2 add annual employment shocks to industry sectors of prior employment, neighborhood characteristics, and dummy variables for ownership sector of prior employment as control variables. The results reported for the baseline model are robust to these inclusions. In addition, a five percent negative change in the log of state-sector employment in a worker's prior industrial sector is associated with a statistically significant 1.4 percent reduction in the reemployment probability of men (line 8 and column 2 of Table 2). Given that annual negative shocks to employment during the restructuring period were well over 20 percent in some industrial sectors, these demand effects are quite severe for men. However, we do not find evidence that similar labor demand shocks have an impact on the reemployment rates of women.

To investigate the effects of public subsidies, family demographics, and access to information on reemployment rates, we add to our base specification a full set of $\mathbf{B}$ and $\mathbf{S}$ variables and report the results in Table 3. This logit hazard model specification includes dummy variables for access to unemployment benefits and pensions, household and family demographic characteristics, and measures of access to information. In alternate specifications, $\mathbf{S}$ includes the number of own-generation relatives and the presence of local employment referral services. We find that the ability to receive unemployment subsidies, either a xiagang subsidy or unemployment insurance payment, lowers the probability that a man will be reemployed within a 
year by 34 percent in column 1 . However, such access has no statistically significant impact on the reemployment rate of women. Given that we expect a positive bias on access to benefits if access is correlated with tenure, we conclude that the disincentive effect on the reemployment rate of men is significant. This large disincentive effect contrasts with the findings of Appleton et al. (2002), who pool men and women rather than examining reemployment rates by gender, and also with studies of other transition countries, e.g., Svejnar (1999). In contrast, the lack of a statistically significant incentive effect for women is consistent with the findings of Ham et al. (1999) for the Czech Republic. This result is likely due to decisions to exit the labor force that are independent of the availability of unemployment benefits. Early-retirement dummies reflect wealth effects that may have an impact on the reservation wages of workers. Men and women receiving early-retirement benefits are 77 and 60 percent less likely to be reemployed within a year.

Regarding the influence of household demographic structure, we find that the magnitudes of the coefficients suggest that household structure may have an impact on the labor supply decisions of members, even though all of them are not statistically significant. As Table 3 indicates, switching a man from married to unmarried status reduces the probability of reemployment within a year by 35 percent. $^{29}$ However, we do not find a similar impact of marital status on the labor supply of women. Interestingly, neither the presence of young children nor of elderly people affects male or female reemployment probabilities in a statistically significant manner. The labor supply of women is influenced most strongly by the existence and age of adult children. The existence of an adult child between 18 and 22, whether or not the child

\footnotetext{
${ }^{29} \mathrm{~A}$ causal interpretation of this coefficient should be avoided because the dummy for marital status includes both the effect of being married and a dimension of unobserved ability that may help to attract a spouse in the period prior to the involuntary loss of a job. If higher ability men are more likely to be married, we would expect a positive coefficient on the marital status dummy, as Korenman and Neumark (1991) discuss.
} 
is a household member, raises the one-year reemployment rate of women by 58 percent. In other words, the existence of a child aged 18 to 22 increases the intensity of search or lowers the reservation wage at which a dislocated female worker will accept a job offer. This result is most likely related to the need to pay college tuition. Indeed, if instead we ignore endogeneity concerns and include a dummy for an adult child in college, the reemployment rate jumps to more than 150 percent. In contrast, a woman with an adult child over 28 is 17 percent less likely to be reemployed within a year. When adult children are over 28 , mothers may find that home production as caregivers for grandchildren or for the elderly has a higher return than employment. Finally, unlike for women, the effect of adult children on the reemployment rate of men is much smaller and statistically insignificant.

We find evidence that having a large social network speeds up the process of reemployment, which suggests that lack of information may indeed be an important factor in explaining the slow rate at which some dislocated workers find new employment. As Table 3 indicates, if the number of own-generation relatives living within the city increases from 3 to 6 , the one-year reemployment probabilities increase by 12 and 13 percent for men and women, respectively. Interestingly, the number of a spouse's own-generation relatives living in the city does not affect reemployment probabilities for men or women. As a robustness check, we added interaction terms to see if the social network variable matters more for men, less-educated people, or those in neighborhoods that were poorer or had more non-workers. We found no evidence of any important interaction effects.

In columns (2) and (4) of Table 3, we add a dummy variable to indicate whether or not the RC provides employment referral. We observe a large positive relationship between referral services and one-year reemployment rates at 27 percent for men and 29 percent for women; 
however, these effects are not statistically significant. To investigate the interaction of social network variables and benefit variables, suggested by the theoretical model, we examined an exhaustive set of potential interactions. We found strong evidence only for the interaction of RC referral services and the existence of a college-age child in the women's reemployment rate estimation. In that case, the female annual reemployment rate rises by 143 percent. This sharp increase in reemployment probability underscores the fact that information or referral can be particularly important for those individuals who are strongly motivated to reenter the labor force. $^{30}$

As a caution in interpreting these results, the number of same-generation relatives in a city may be correlated with unobservable dimensions of ability. In addition, the local provision of employment referral services by RCs is correlated with other factors affecting reemployment, such as local labor demand. To investigate the potential bias from such correlations, we regressed key independent variables of interest on the variables used in the base model presented in Table 2 to determine whether they are positively or negatively correlated with observable measures of ability or local labor demand. ${ }^{31}$ We found that years of education is not significantly related to access to public subsidies, number of own-generation relatives, or spouse's own-generation relatives. Hence, we are somewhat less concerned that our social network variables are proxies for unobserved ability. Although we do not think that social networks provide social insurance, our estimates of the effect of social networks on reemployment probabilities would be biased downward if this were true.

When we examine the results for impact of the provision of employment referral services by RCs, we find that neighborhood characteristics that are likely to increase the demand for labor

\footnotetext{
${ }^{30}$ Detailed results are not presented due to space limitations and are available upon request from the authors.

${ }^{31}$ Detailed results are not presented due to space limitations and are available upon request from the authors.
} 
predict the existence of referral services. Since placement of employment referral is correlated positively with other demand and supply factors likely to affect reemployment, we must interpret the correlation between presence of referral service and reemployment rates cautiously. Nonetheless, the fact that employment referral interacts strongly with having a child of college age in affecting the reemployment probability of women but interactions with other neighborhood labor-demand variables, e.g., log average neighborhood consumption per capita, average years of schooling, and commercialization of housing, are not significant suggests that our measured effects are due to informational access rather than labor demand.

\section{Conclusion}

In all economies, workers who suffer dislocation due to bankruptcy or restructuring of enterprises face considerable difficulty finding new employment. These difficulties may be even greater for older workers and for those with less human capital. In transition economies, the effect of isolation from information about employment and confusion over the process of job search exacerbates problems in finding new employment. Even though China is a rapidly growing economy with average per capita income rising by nearly eight percent per year over the last twenty years, this growth has not been fully inclusive of all of China's urban workers in recent years. In this paper, we provide empirical evidence on the determinants of reemployment probabilities of dislocated workers in urban China. Our results confirm a strong positive association between education and the probability of reemployment and a negative relationship between age and reemployment, with these effects being particularly strong for women. Furthermore, we find that China's system of xiagang and unemployment benefits has a significant negative impact on the reemployment rates of male recipients. In contrast, we find 
that the reemployment probabilities of women are influenced significantly by family demographic characteristics, especially the existence of adult children. The importance of family circumstances in female reemployment suggests that family considerations might help to explain the rapid decrease in female labor force participation in China.

We highlight the importance of access to information, especially through social networks, for unemployment duration. Using a plausibly exogenous measure of social networks, we find significant positive effects of social networks on reemployment probabilities. We also provide suggestive evidence that employment referral services provided by local residents' committees play an important information role in reemployment, especially for women who are highly motivated to find a new job. This finding has policy implications indicating the benefit of programs that strengthen employment referral services. However, a broader policy implication is the importance of information and social networks in particular, especially for transition economies in which job search options remain limited. Another important implication for policy makers in China and elsewhere who are designing social insurance programs is that some aspects of the safety net may create significant disincentive effects for reemployment. In China, the disincentive is particularly strong for men. More careful examination of the effect of benefit duration and wage replacement rates is warranted for the design of unemployment insurance systems with less pronounced disincentives for job search. 


\section{References}

Appleton, Simon, John Knight, Lina Song, and Qingjie Xia (2002). "Labor Retrenchment in China: Determinants and Consequences,” China Economic Review 13: 252-275.

Bane, Mary Jo and David Ellwood (1983). "The Dynamics of Dependence: The Routes to SelfSufficiency,” Office of the Assistant Secretary for Planning and Evaluation, U.S. Department of Health and Human Services.

Bellmann, Lutz, Saul Estrin, Lehmann Hartmut and Jonathan Wadsworth (1995). “The Eastern German Labor Market in Transition: Gross Flow Estimates from Panel Data,” Journal of Comparative Economics 20(2): 139-170.

Blanchard, Olivier, and Michael Kremer (1997). "Disorganization," Quarterly Journal of Economics, v112, n4 (November 1997): 1091-1126.

Blank, Rebecca and Patricia Ruggles (1996). "When Do Women Use AFDC and Food Stamps: The Dynamics of Eligibility versus Participation,” Journal of Human Resources 31 (1996), 57-89.

Boeri, Tito, and Katherine Terrell (2002). "Institutional Determinants of Labor Reallocation in Transition,” Journal of Economic Perspectives 16(1): 51-76.

Cai, Fang, John Giles and Xin Meng (2006). "How Well Do Children Insure Parents Against Low Retirement Income? An Analysis Using Survey Data from Urban China,” Journal of Public Economics (in press).

Calvo-Armengol, Antoni and Matthew Jackson (2004). “The Effects of Social Networks on Employment and Inequality,” American Economic Review v94, n3 (June 2004): 426-54.

Card, David and Craig Riddell (1997). "Unemployment in Canada and the United States: A 
Further Analysis," in Trade, Technology and Economics: Essays in honour of Richard G. Lipsey (Eaton, B. Curtis; Harris, Richard G., eds): 47-87.

Choate, Allen C. (1998). "Local Governance in China, Part II: An Assessment of Urban Residents Committees and Municipal Community Development,” The Asia Foundation Working Paper Series, No. 10, November 1998.

Davidson, Carl and Stephen Woodbury (1996). “Unemployment Insurance and Unemployment: Implications of the Reemployment Bonus Experiements," in Advisory Council on Unemployment Compensation: Background Papers, Vol. 3. Washington, DC: ACUC, January.

Devine, Theresa J., and Nicholas M. Kiefer. 1991. Empirical Labor Economics: The Search Approach (New York and Oxford, Oxford University Press).

Ellwood, David (1986). “Targetting Would-Be Long-Term Recipients of AFDC,” Office of the Assistant Secretary for Planning and Evaluation, U.S. Department of Health and Human Services.

Klerman, Jacob, and Steven J. Haider (2004). "A Stock-Flow Analysis of the Welfare Caseload." Journal of Human Resources, 39(4):865-886.

Giles, John, Albert Park, and Fang Cai (2006). “How Has Economic Restructuring Affected China’s Urban Workers?” China Quarterly 185 (March): 61-95.

Giles, John, Albert Park, and Juwei Zhang (2005). “What is China’s True Unemployment Rate?,” China Economic Review Vol. 16(2): 149-170.

Ham, John C., Jan Svejnar, and Katherine Terrell (1998). "Unemployment and the Social Safety Net During Transitions to a Market Economy: Evidence from the Czech and Slovak 
Republics” in American Economic Review, Vol 88 (5): 1117-1142.

Ham, John C., Jan Svejnar, and Katherine Terrell (1999). “Women’s Unemployment during Transition: Evidence from Czech and Slovak Micro-Data,” Economics of Transition 7(1): 47-78.

Hamermesh, Daniel S. (1977). Jobless Pay and Economy, The Johns Hopkins University Press, Baltimore, 1977,

Hoynes, Hilary Williamson (2000). "Local Labor Markets and Welfare Spells: Do Demand Conditions Matter?” in Review of Economics and Statistics, 82(3): 351-368.

Hoynes, Hilary and Thomas MaCurdy (1994). "Has the Decline in Benefits Shortened Welfare Spells?” American Economic Review v84, n2 (May 1994): 43-48.

Ionnides, Yannis, and Linda Datcher Loury (2004). "Job Information Networks, Neighborhood Effects, and Inequality," Journal of Economic Literature 42: 1056-1093.

Kalbfleisch, J.D., and R.L. Prentice (1980). The Statistical Analysis of Failure Time Data, Wiley and Sons, New York 1980.

Katz, Lawrence F. and Bruce D. Meyer, Bruce (1990). “The Impact of the Potential Duration of Unemployment Benefits on the Duration of Unemployment," Journal of Public Economics v41, n1 (February 1990): 45-72.

Klerman, Jacob, and Steven J. Haider (2004). "A Stock-Flow Analysis of the Welfare Caseload." Journal of Human Resources, 39(4):865-886.

Korenman, Sanders and David Neumark (1991). "Does Marriage Really Make Men More Productive?” Journal of Human Resources v26, n2 (Spring 1991): 282-307. 
Lancaster, Tony (1990). The Econometric Analysis of Transition Data, Cambridge University Press.

Micklewright, John and Gyula Nagy (1996). "Labour Market Policy and the Unemployed in Hungary,” European Economic Review v40, n3-5 (April 1996): 819-28.

Micklewright, John and Gyula Nagy (1994). "How Does the Hungarian Unemployment Insurance System Really Work? Economics of Transition v2, n2 (June 1994): 209-32.

Ministry of Labor (2002). China Labor and Social Security Yearbook (Beijing: Ministry of Labor).

Ministry of Labor and Social Security (2002). Selected Important Documents on Labor and Social Security in the New Period. Document Research Office of the Central Committee of the Communist Party of China, China Labor and Social Security Publishing House and Central Document Publishing House, 2002.

Montgomery, James D. (1991). "Social Networks and Labor-Market Outcomes: Toward an Economic Analysis,” American Economic Review v81, n5 (December 1991): 1407-18.

Mortenson, Dale T., and Christopher A. Pissarides. 1999. "New Developments in Models of Search in the Labor Market," in O. Ashenfelter and David Card, eds., Handbook of Labor Economics, Volume 3 (Elsevier).

Neumann, George. 1997. "Search Models and Duration Data,” in Pesaran, M. Hashem, and Peter Schmidt, eds., Handbook of Applied Econometrics, V. 2: Microeconomics (Oxford and Malden, MA: Blackwell Publishers).

Puhani, Patrick A. (2000). "Poland on the Dole: The Effect of Reducing the Unemployment Benefit Entitlement Period during Transition,” Journal of Population Economics v13, n1 
(February 2000): 35-44.

Read, Benjamin (2000). "Revitalizing the State’s Urban 'Nerve Tips',” in The China Quarterly, No. 163 (September 2000): 806-820.

Read, Benjamin (2003). State, Social Networks and Citizens in China's Urban Neighborhoods, Department of Government, Harvard University, Ph.D. Dissertation.

Rogerson, Richard, and Randall Wright. 2002. "Search-Theoretic Models of the Labor Market: A Survey,” Penn Institute

Svejnar, Jan (1999). "Labor Markets in the Transitional Central and East European Economies,” in Ahsenfelter, O., and D. Card, eds., Handbook of Labor Economics, Volume 3 (Elsevier Science), pp. 2809-2857.

Zhang, Juwei (2003). Urban Xiagang, Unemployment and Social Support Policies: A Literature Review of Labor Market Policies in Transitional China, Report to the World Bank. 


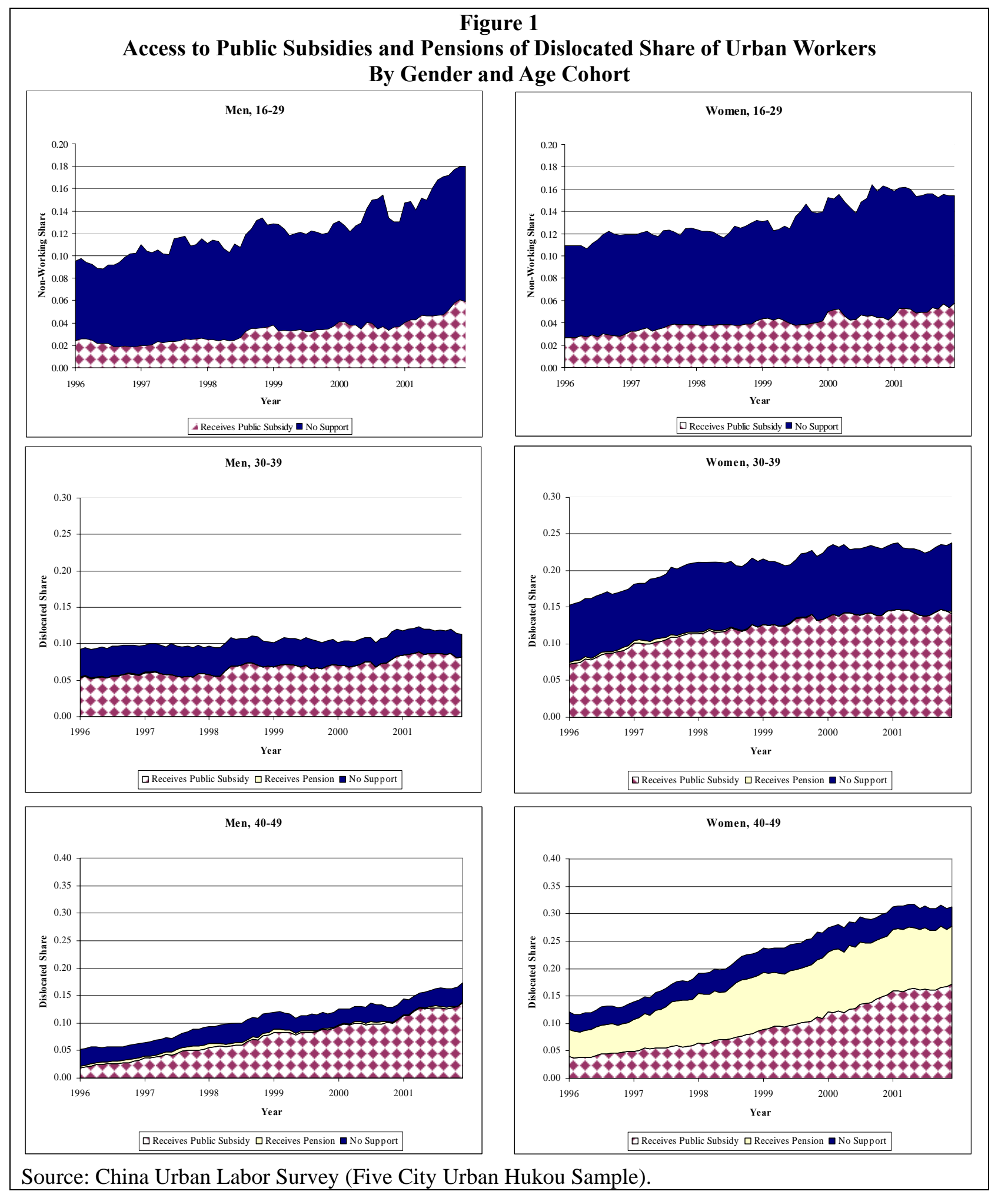




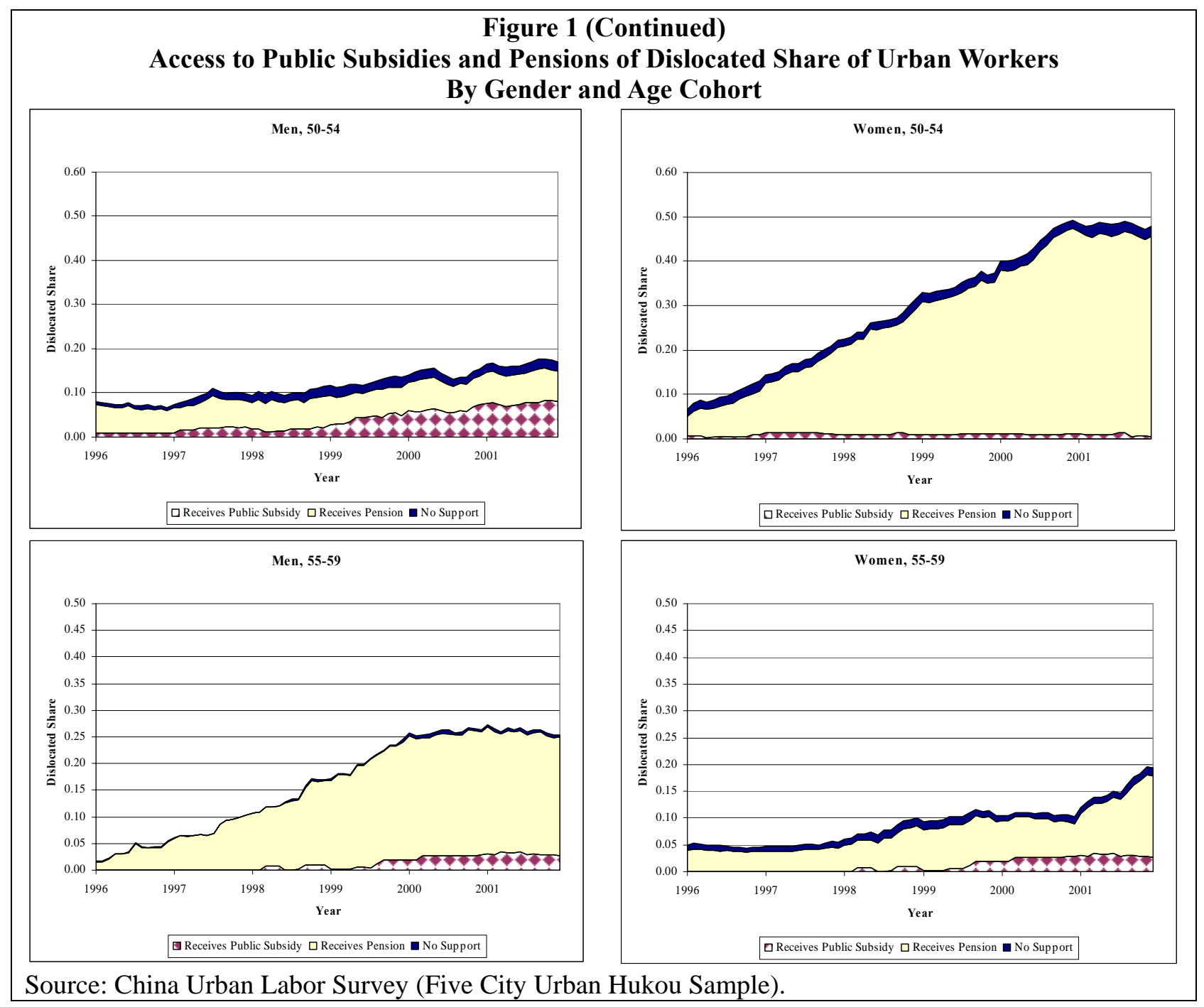


Figure 2

Duration of Non-Working Spells and Age
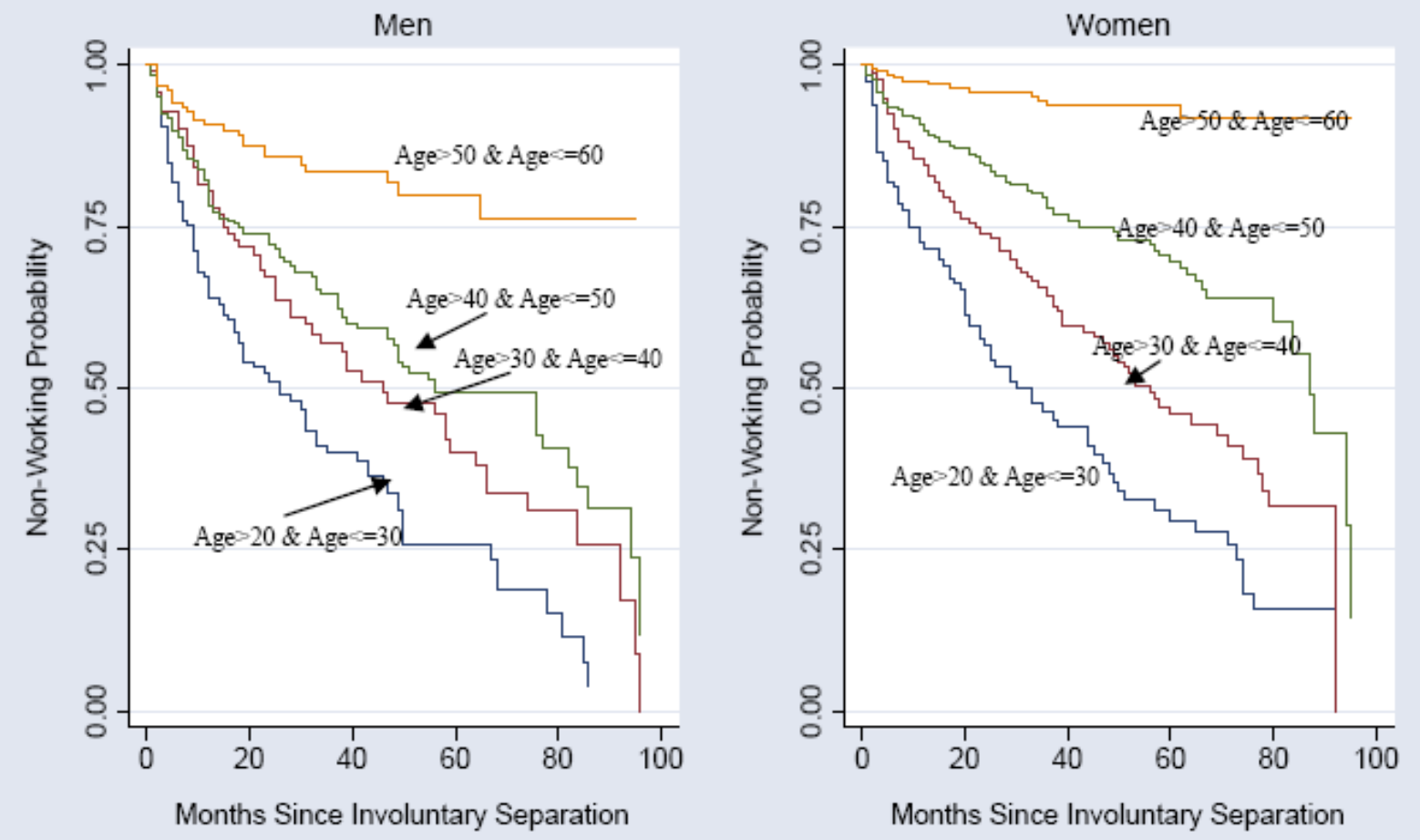
Figure 3

Duration of Non-Working Spells and Educational Attainment
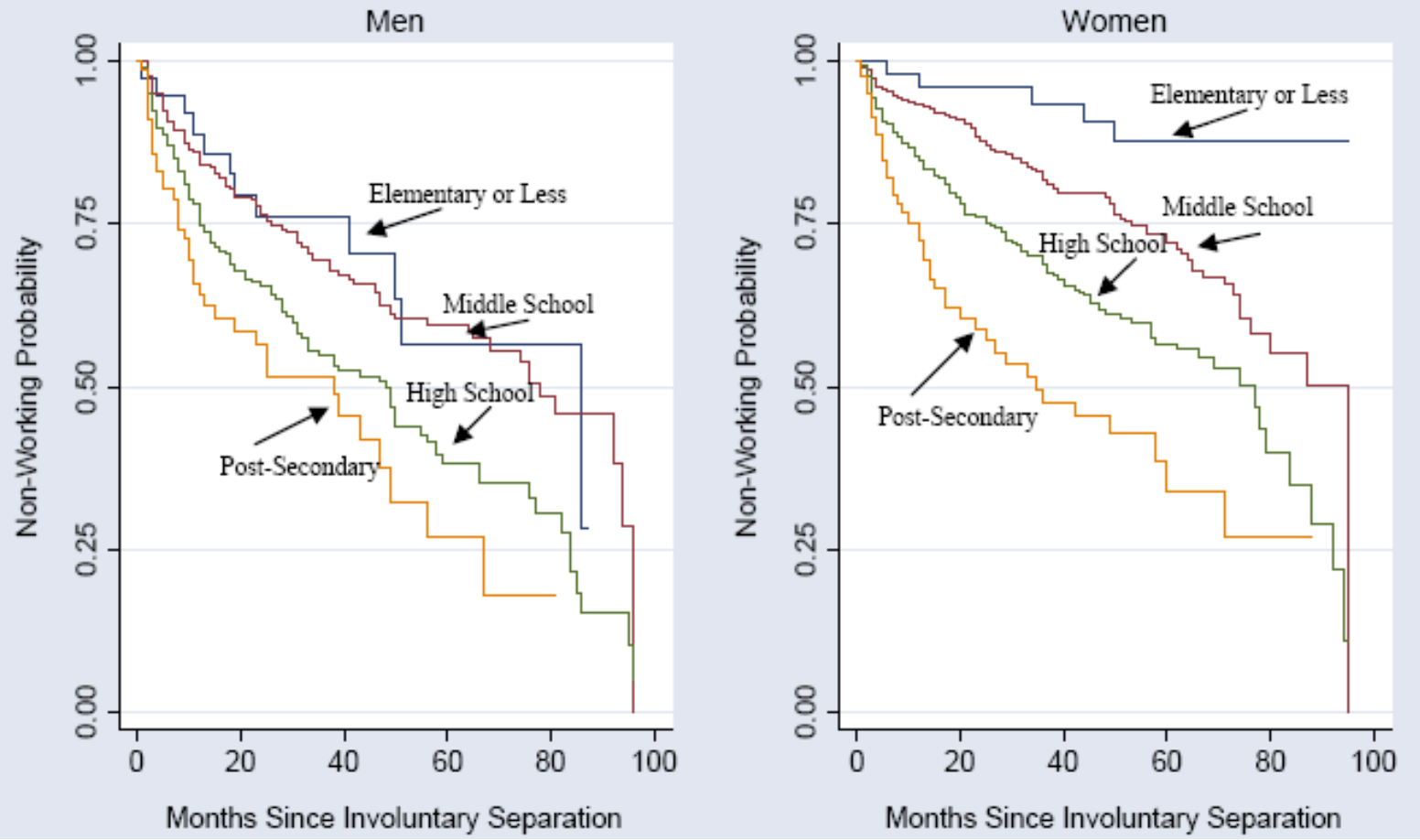
Figure 4

Duration of Non-Working Spells and Eligibility for Formal Support
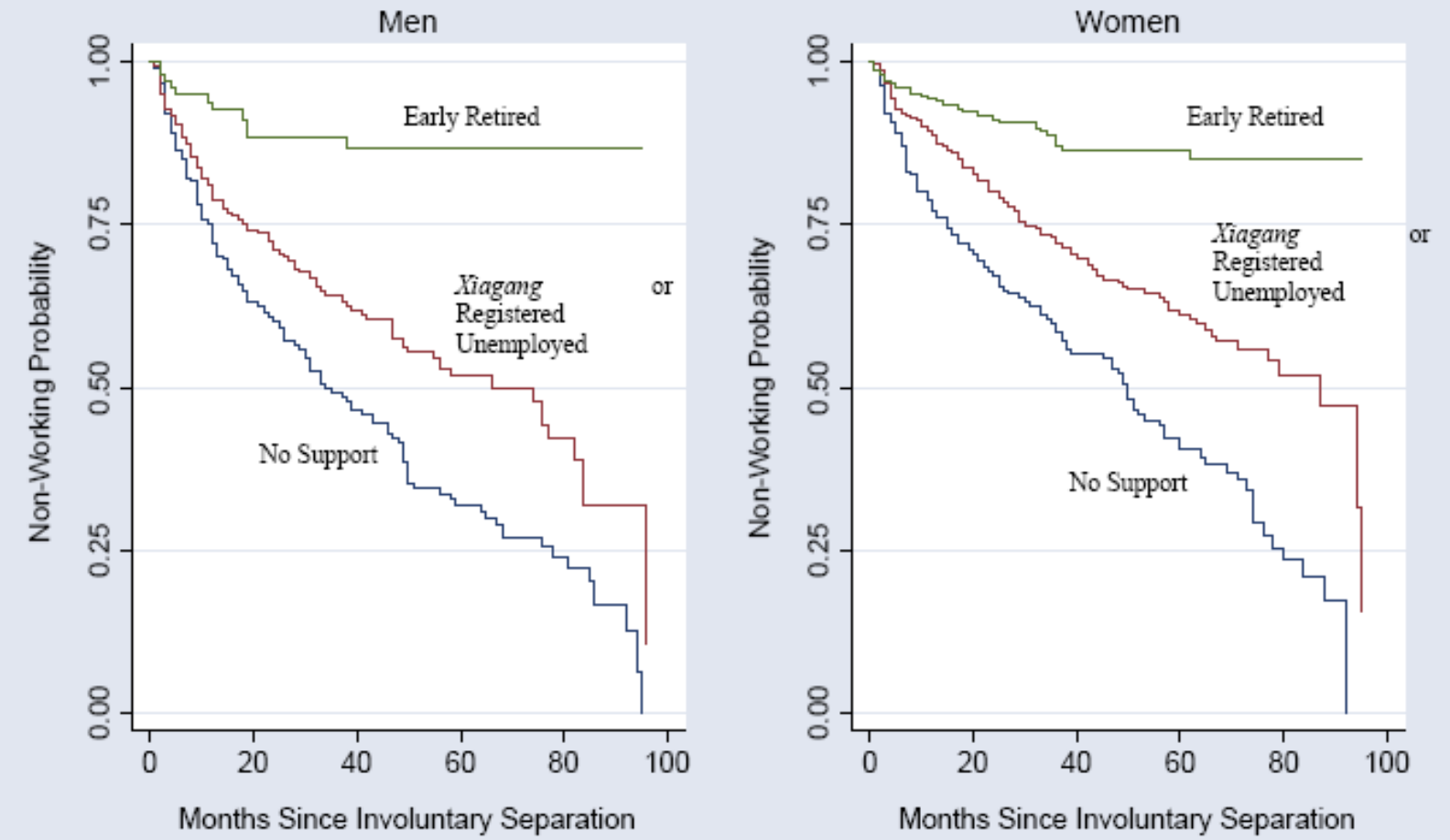
Figure 5

Duration of Non-Working Spells and Number of

Own-Generation Relatives Living in the City
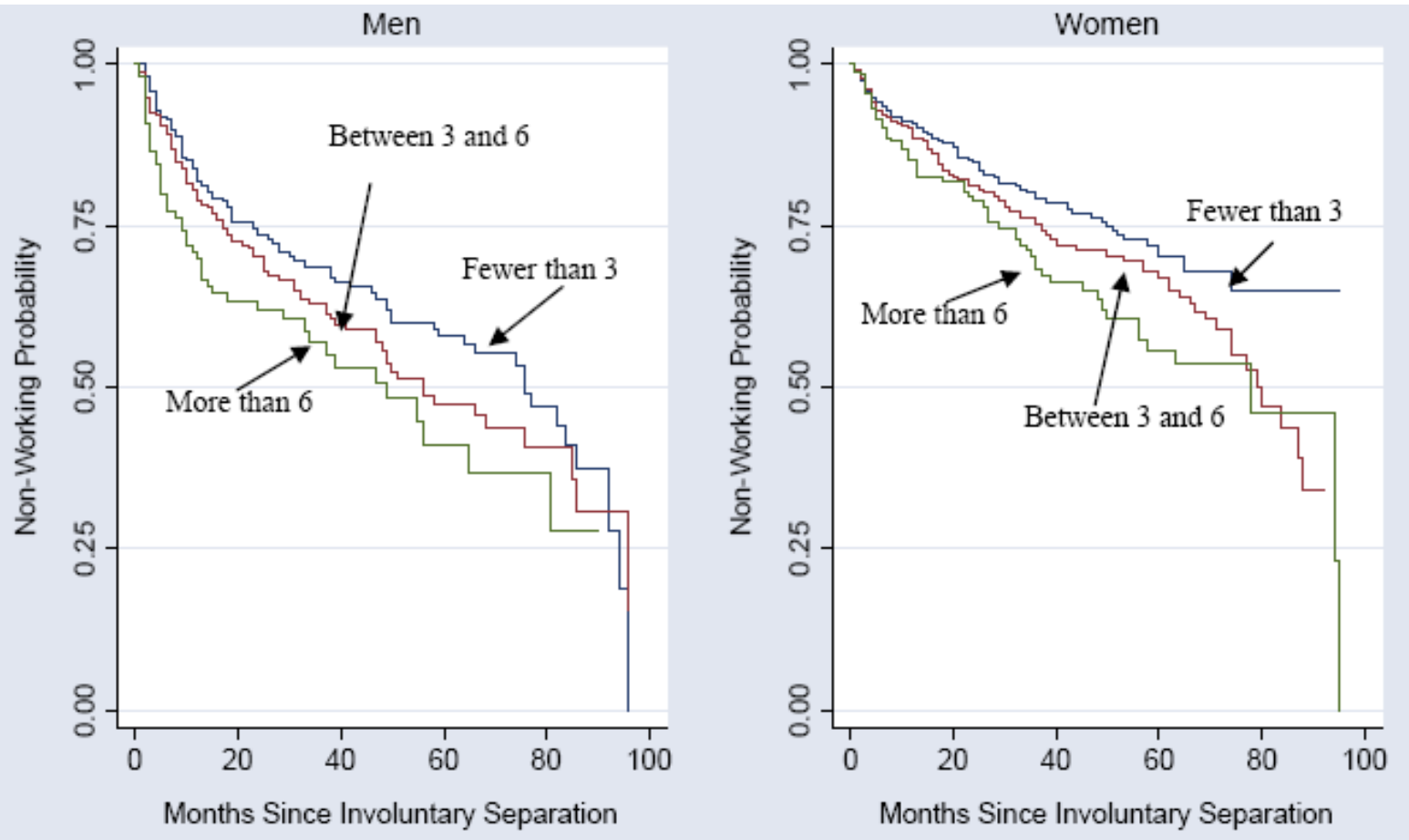
Table 1

Household and Family Structure of Involuntarily

Laid-Off Working-Age Adults

Measured in Month after Layoff

\begin{tabular}{lcc}
\hline & Men & Women \\
\hline Living in the Household & & \\
Household Size & 3.27 & 3.13 \\
Married & 0.82 & 0.91 \\
Children Under 6 & 0.11 & 0.08 \\
Children Between 6 \& 12 & 0.20 & 0.20 \\
Children Between 12 \& 18 & 0.29 & 0.29 \\
Working Age Adults & 2.36 & 2.14 \\
Retirees Under 65 & 0.11 & 0.24 \\
Over 65 & 0.19 & 0.18 \\
& & \\
Living in the City & & \\
Children 18 or Older and Less Than 23 & & 0.28 \\
Children 23 or Older and Less Than 28 & 0.26 & 0.21 \\
Children 28 or Older & 0.21 & 0.31 \\
Number of Own-Generation Relatives & 0.38 & 4.06 \\
Number of Spouse's Own-Generation Relatives & 3.75 & 3.39 \\
& 3.17 & \\
\hline
\end{tabular}

Notes

i. Working-Age Adults are men between 18 and 60 and women between 18 and 55 .

ii. Retirees Under 65 include men between 60 and 65 and women between 55 and 65.

iii. Household structure is measured in the first-month of a non-working spell. Individuals with more than one non-working spell have household and family structure reported at the first month of each non-working period.

iv. The CULS includes detailed information about the age, marital status, education, and employment of all household members and all adult children regardless of whether or not they are household members. 
Table 2

The Impact of Education, Age, Employment Background and Labor Demand on Re-Employment Rates

Sample: Working Age Adults Involuntarily Leaving Previous Employment

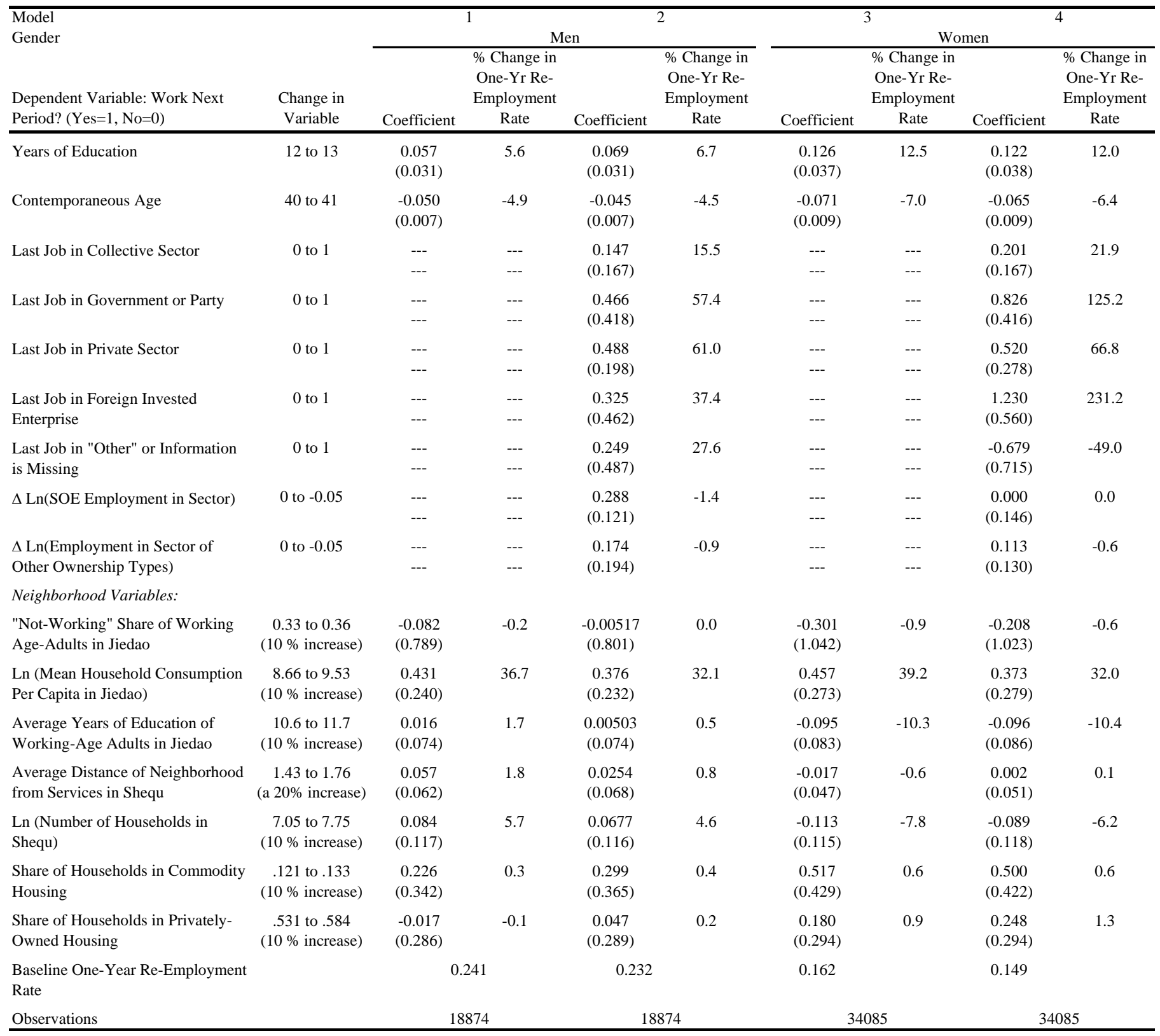

Notes:

i. $\quad$ Cluster corrected robust standard errors are shown in parentheses.

ii. All models include dummy variables for one to six months unemployed, and a quartic in time unemployed for months seven and higher.

iii. City and year fixed effects are included and significant in all models.

iv. The state sector is the omitted prior ownership sector.

v. For each model, we show the coefficient from the logit regression, and use monthly marginal effects to calculate the percentage change in the annual baseline reemployment rate for the change in the variable listed in the left column.

vi. The baseline hazard for the models above assumes: Years of Education=12, Age=40, Household Size=3, Married=1, Children Under $6=0$, Children Between 6 and 12 = 0, Children Between 12 and 18=0, Mandatory Retirees Under 65 = 0, Residents Over 65=0, Xiagang=0, Registered Unemployed=0, Early Retired=0, Last Job in State Sector=0, Last Job in Collective Sector=0, Last Job in Government or Party $=0$, Last Job in Private Sector $=0$, Last Job in Foreign Invested Enterprise $=0$, Change in Log (Provincial SOE Employment in Industry Sector of Prior Job) = 0.0, Change in Log (Provincial Employment in Other Ownership Types in Industry Sector of Prior Job) $=0.0$. 
Table 3

The Impact of Access to Benefits and Information/Referral on Re-Employment Rates

Sample: Working Age Men and Women Involuntarily Leaving Previous Employment from January 1993-October 2001

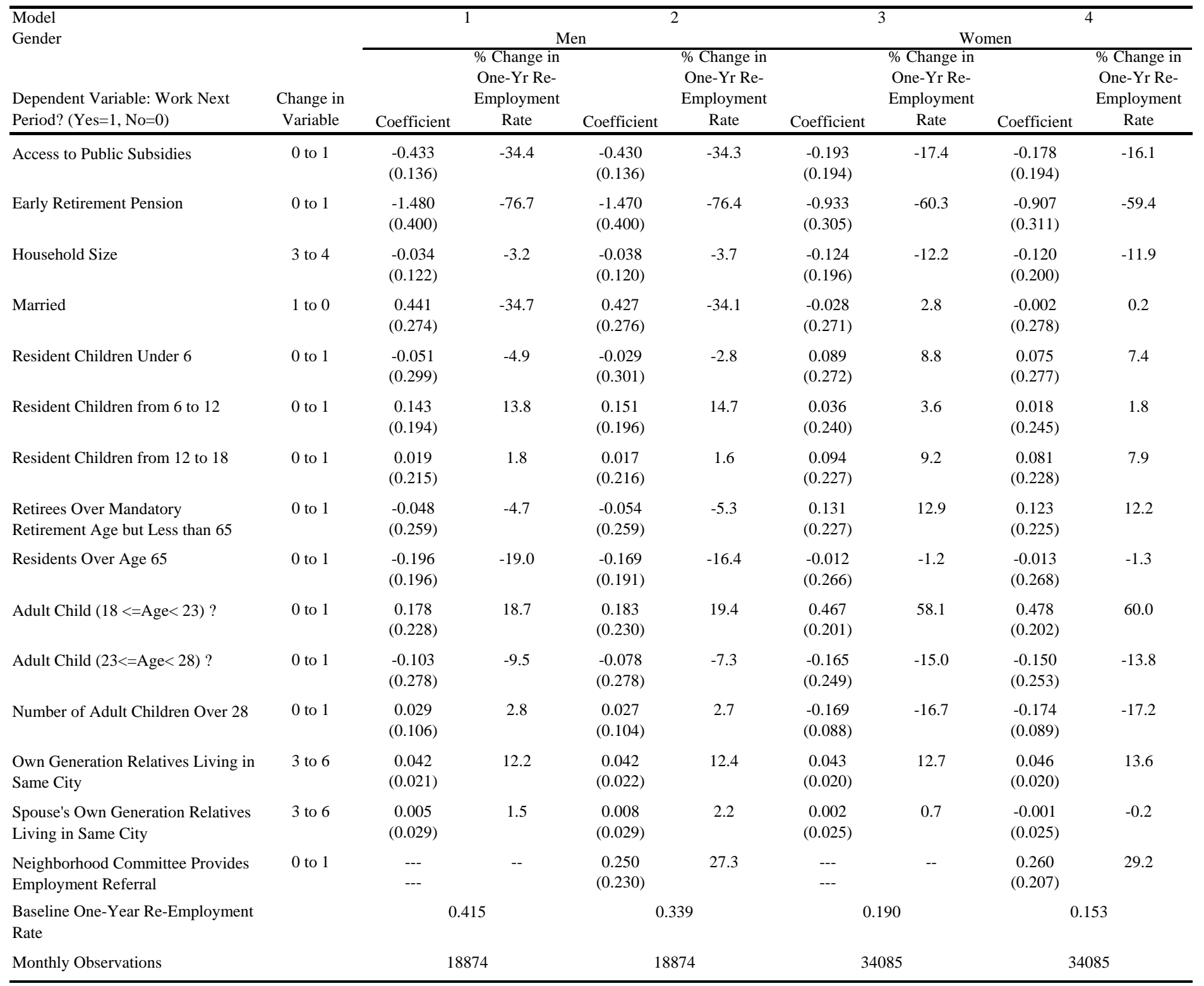

Notes:

i. Cluster corrected robust standard errors are shown in parentheses.

ii. All models include the same regressors shown in columns 2 and 4 of Table 2; coefficients are not shown but are available upon request.

iii. All models include dummy variables for one to six months unemployed, and a quartic in time unemployed for months seven and higher.

iv. $\quad$ City and year fixed effects are included and significant in all models.

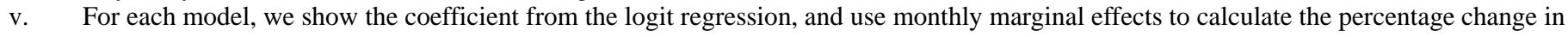
the annual baseline reemployment rate for the change in the variable listed in the left column.

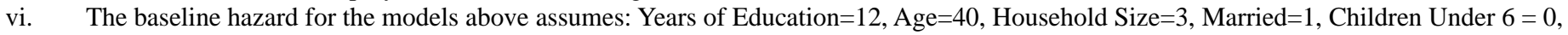
Children Between 6 and $12=0$, Children Between 12 and 18=0, Mandatory Retirees Under 65 = 0, Residents Over 65=0, Xiagang=0, Registered Unemployed=0, Early Retired=0, Last Job in State Sector=0, Last Job in Collective Sector=0, Last Job in Government or Party = 0, Last Job in Private Sector = 0, Last Job in Foreign Invested Enterprise = 0, Change in Log (Provincial SOE Employment in Industry Sector of Prior Job) = 0, Change in Log (Provincial Employment in Other Ownership Types in Industry Sector of Prior Job) = 0, Respondent's Own Generation Relatives = 3, Spouse's Own Generation Relatives = 3, Neighborhood Has Employment Referral Service=0, and neighborhood variables are evaluated at mean values. 